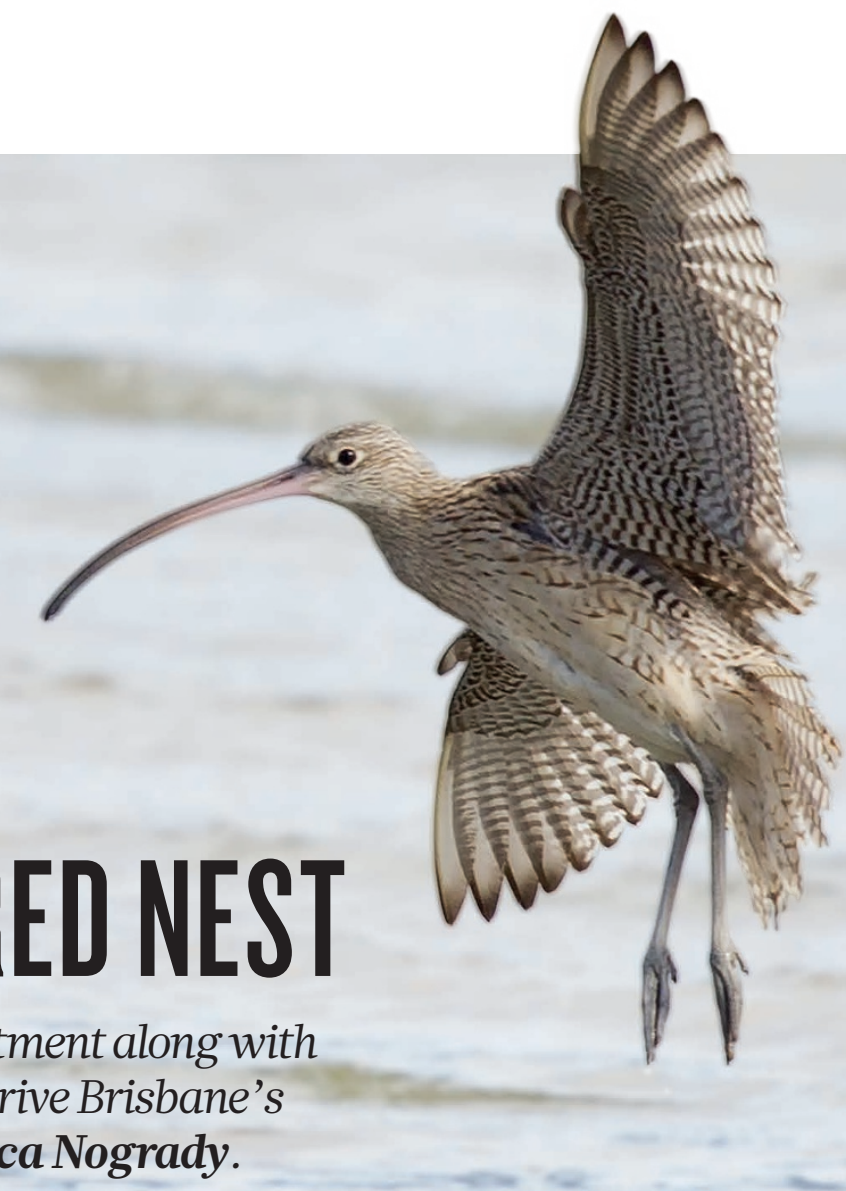

\title{
A WELL-FEATHERED NEST
}

Significant state government investment along with philanthropic largesse has helped drive Brisbane's research performance, writes Bianca Nogrady.

An Eastern curlew lands at the edge of a coastal mudflat in Queensland, a place rich in opportunity for bird-watchers and a centre for high-quality science.

\section{BRISBANE}

POPULATION: 2,308,700

INSTITUTIONS IN THE INDEX: 28

WEIGHTED FRACTIONAL COUNT 2012: 106.23
2015: 135.70

\section{ARTICLE COUNT: 611}

\section{SUBJECT STRENGTH: LIFE SCIENCES}

\footnotetext{
"I'm an obsessive bird watcher and Brisbane is one of the most awesome places to be in nature," says conservation scientist Richard Fuller from the University of Queensland. For Fuller, a world leader in modern conservation science, the natural wonders of Brisbane are closely tied to its scientific benefits - a key factor that lured him to the city from the United Kingdom in 2008. Last year, he and colleagues published the results of an international study in the journal Science on the impact of protected areas on migratory birds. "Every year, we do a 24-hour 'twitchathon' - a race to see how many species of birds we can see - and last year we saw 220 species in Brisbane in one day."
}

Brisbane, the riverside capital of the state of Queensland, is fast becoming an epicentre for high-quality science. Between 2012 and 2015, the contribution to the 68 top-tier natural science journals included in the Nature Index from scientists in Brisbane increased more than from any other Australian capital.

Last year Brisbane was the country's third-largest contributor to the index, after Melbourne and Sydney, thanks largely to its strength in life sciences research. Brisbane is also home to the Nature Index's top Australian university for 2015, the University of Queensland. Clearly, it takes more than great weather and beaches to lure scientists to a city, especially when Sydney and Melbourne also offer attractive lifestyles. Frank Gannon, director of the inner-Brisbane based Queensland Institute of Medical Research (QIMR) Berghofer Medical Research Institute, says while its quality of life is "terrific", Brisbane's research infrastructure is a big drawcard. A decade of significant state investment has resulted in some "truly beautiful buildings and advanced laboratories," Gannon says. His own institute has facilities to manufacture cell-based therapies, as well as a commercial phase I/II clinical trials facility.

On the other side of town, Australia's newest medical research and biopharmaceutical facility, the Translational Research Institute (TRI), led by immunologist Ian Frazer, who spearheaded the development of the first cervical cancer vaccine, includes facilities for imaging, proteomics, and human clinical research. The TRI received $\$ 50$ million from American businessman Chuck Feeney's Atlantic Philanthropies - the country's largest single donation to a medical research institute. All up, Brisbane's universities, medical research institutes and hospitals have received more than \$250 million from Feeney. Researchers have also benefitted from significant state government funding, particularly under former premier Peter Beattie. His government's 'Smart State' initiative in the early 2000s injected $\$ 3.4$ billion into research and development, producing 36 new research institutes, particularly in the biomedical sciences, and more than 230 research scholarships and fellowships over a decade. "Brisbane is a good example of where an investment in research was made some time ago and is now starting to pay off," says Darren Saunders, a cancer researcher based at the University of New South Wales in Sydney.

While Brisbane's research growth is likely due to many factors, Saunders says more affordable housing may also have played a role in persuading overseas scientists to move there. "I've heard anecdotally we've had trouble in Sydney convincing scientists to come here, because it's a very expensive place to live," he says. 